\title{
Neuropharmacological Targets for Drug Action in Vestibular Sensory Pathways
}

\author{
Choongheon Lee ${ }^{1}$ and Timothy A. Jones ${ }^{2}$ \\ ${ }^{1}$ Department of Otolaryngology, Washington University School of Medicine, Saint Louis, MO, \\ ${ }^{2}$ Department of Special Education and Communication Disorders, University of Nebraska-Lincoln, Lincoln, NE, USA
}

\author{
Received July 11, 2017 \\ Revised September 1, 2017 \\ Accepted September 1, 2017
}

\author{
Address for correspondence \\ Choongheon Lee, $\mathrm{PhD}$ \\ Department of Otolaryngology, \\ Washington University \\ School of Medicine, \\ 660 South Euclid Avenue, \\ Saint Louis, MO 63110, USA \\ Tel +1-314-121-3496 \\ Fax +1-314-362-0315 \\ E-mail c.lee@wustl.edu \\ Timothy A. Jones, $\mathrm{PhD}$ \\ Department of Special Education and \\ Communication Disorders, \\ University of Nebraska-Lincoln, \\ 304 Barkley Memorial Center, \\ Lincoln, NE 68583, USA \\ Tel +1-402-472-5100 \\ Fax +1-402-472-3814 \\ E-mail timothy.jones@unl.edu
}

The use of pharmacological agents is often the preferred approach to the management of vestibular dysfunction. In the vestibular sensory pathways, the sensory neuroepithelia are thought to be influenced by a diverse number of neuroactive substances that may act to enhance or inhibit the effect of the primary neurotransmitters [i.e., glutamate (Glu) and acetylcholine (ACh)] or alter their patterns of release. This review summarizes various efforts to identify drug targets including neurotransmitter and neuromodulator receptors in the vestibular sensory pathways. Identifying these receptor targets provides a strategic basis to use specific pharmacological tools to modify receptor function in the treatment and management of debilitating balance disorders. A review of the literature reveals that most investigations of the neuropharmacology of peripheral vestibular function have been performed using in vitro or ex vivo animal preparations rather than studying drug action on the normal intact vestibular system in situ. Such noninvasive approaches could aid the development of more accurate and effective intervention strategies for the treatment of dizziness and vertigo. The current review explores the major neuropharmacological targets for drug action in the vestibular system.

J Audiol Otol 2017;21(3):125-132

KEY WORDS: Dizziness · Vertigo · Peripheral vestibular system · Neuroactive substance · Vestibular suppressant.

\section{Introduction}

Dizziness may be caused by many disturbances in central and peripheral neural function. Vertigo, dizziness, and disequilibrium consistently rank among the most common complaints experienced by individuals with vestibular dysfunction. Moreover, vestibular deficits appear to be among the most common causes of dysequilibrium symptoms requiring medical intervention. Decreased function of the peripheral vestibular system can result in decreased visual acuity during head movements and a degradation of postural control. The management of dizziness related symptoms has mostly involved the use of pharmacological agents during the early acute

This is an Open Access article distributed under the terms of the Creative Commons Attribution Non-Commercial License (http://creativecommons.org/licenses/by-nc/4.0/) which permits unrestricted non-commercial use, distribution, and reproduction in any medium, provided the original work is properly cited. phase of symptom onset. The common objective of drug treatment is to suppress vestibular sensory input. This is thought to reduce conflicting sensory input, control undesirable perceptions, and improve the quality of life of patients.

Vestibular signals originate from the sensory organs of the three semicircular canals and two macular organs within the petrous portion of the temporal bone (Fig. 1). The vestibular neuroepithelium including hair cells, supporting cells as wells as afferent and efferent neurons are thought to interact with a diverse number of neuroactive substances (neurotransmitters and neuromodulators), which bind to specific receptors at the postsynaptic membrane. During normal chemical synaptic transmission, these neurotransmitters and modulators are synthesized and stored in presynaptic vesicles and are released into the synapse to bind and act on postsynaptic cell receptors during the transmission and processing of sensory information. Glutamate [Glu or a glutamate-like excitatory amino acid 


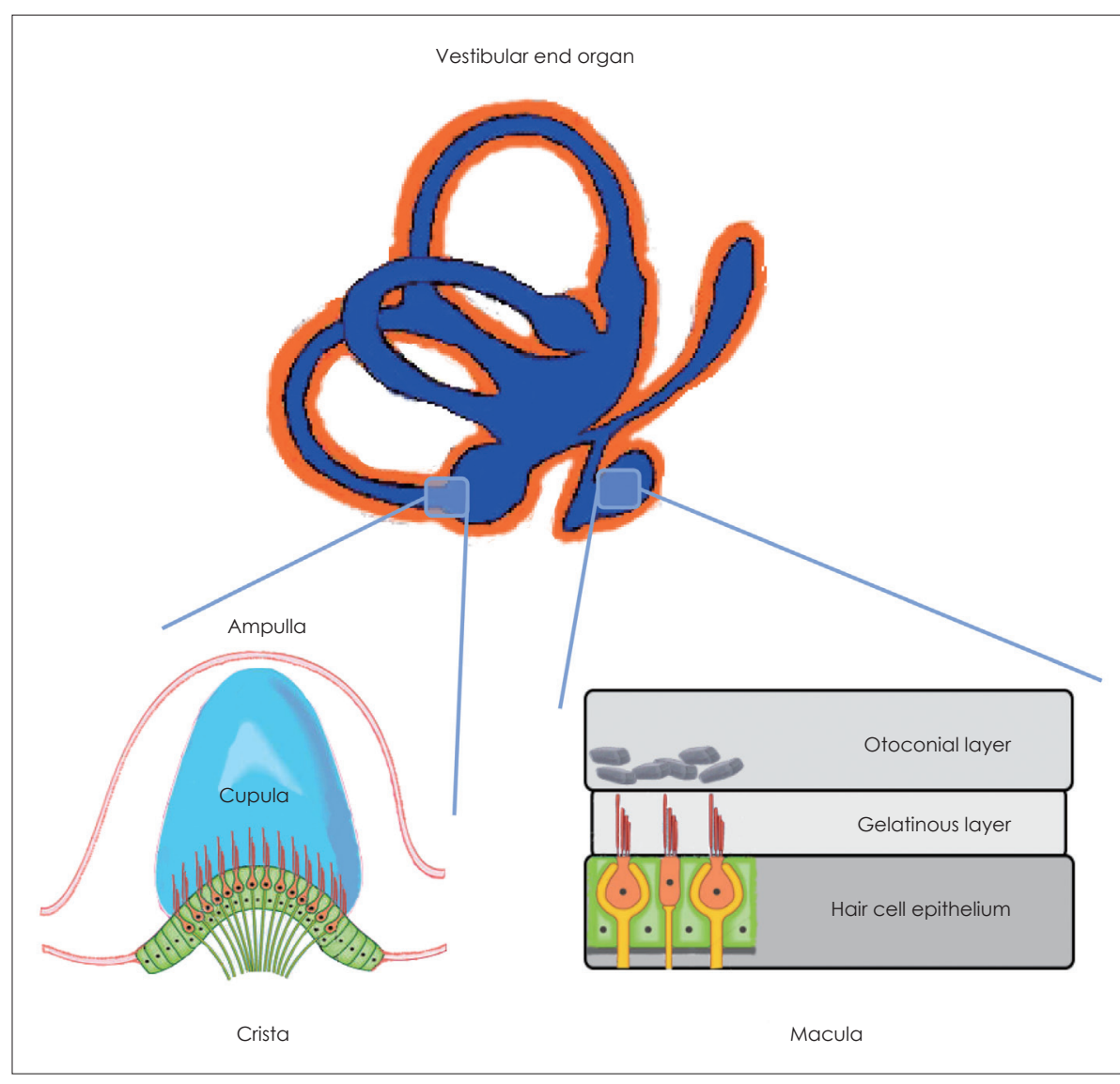

Fig. 1. Schematic illustration of the vestibular end organ (top), which includes the neuroepithelium of the crista ampullaris (lower left) and vestibular macula (lower right). The membranous labyrinth is fluid-filled with endolymph (blue color on top panel) and perilymph (red color). The vestibular system is composed of five organs; three semicircular canals also called "crista sensors" to detect angular accelerations of the head and two otolith organs also called "macular sensors" to detect the linear acceleration of the head. In the crista, kinocilia and stereociliary bundles of hair cells extend into the gelatinous cupula. During angular acceleration of the head, surrounding endolymph lags and moves in the opposite direction in response to rotational acceleration. In the macula, dense calcium carbonate (called "otoconia") are embedded within the otoconial layer, which is greater density than surrounding fluid and tissues of the maculae. During linear acceleration of the head, high density of otoconial layer causes the otoconial layer to shift position relative to the neuroepithelium producing a movement of stereociliary bundles of receptor hair cells.
(EAA) ] and acetylcholine (ACh) are widely accepted as being the primary neurotransmitters released by vestibular hair cells and efferent neural terminals respectively [1,2]. In the peripheral vestibular system, there are a variety of other neuroactive molecules that are thought to be present and may act as modulators at these synapses including $\gamma$-amino butyric acid (GABA), substance $P$, calcitonin gene-related protein (CGRP), and opioid peptides. These neuromodulators may affect the response of neurons by facilitating or inhibiting the effect of the primary neurotransmitters or by altering patterns of release. Neuroactive substances bind with numerous corresponding postsynaptic and presynaptic receptors to mediate neural transmission or modulate the response of postsynaptic neurons. Pharmacologic agents can act at these receptors to alter synaptic messaging. In this way, pharmacological agents have a diverse array of cellular targets that provide a means for modifying sensory transmission. In Fig. 2, many of the possible targets of pharmacological agents in the peripheral vestibular sensory neuroepithelium are summarized.

\section{Neuroactive Substances and Receptors}

Molecular biological, biochemical, and electrophysiological evidences suggest that glutamate, ACh, histamine, enkephalins, GABA, CGRP, and substance $\mathrm{P}$ are all released to some extent as neurotransmitters or modulators in the peripheral vestibular system $[3,4]$. In central vestibular circuits, the vestibular nuclei integrate vestibular, somatosensory, proprioceptive, and visual inputs. These diverse synaptic inputs to the nuclei are also represented by glutamatergic, GABAergic, histaminergic, serotoninergic, and dopaminergic neurons [4]. These neural projections to vestibular nuclei arise mainly from vestibular afferent neurons, spinal afferents, cerebellum, and more rostral descending visual and motor control systems [5]. The following provides an overview of neurotransmitter and neuromodulator receptors identified in the peripheral vestibular neuroepithelium and ganglion as well as in central vestibular nuclei.

\section{Glutamate receptors}

In the vestibular system, glutamate is an EAA and the major neurotransmitter of the vestibular sensory hair cells [1]. 


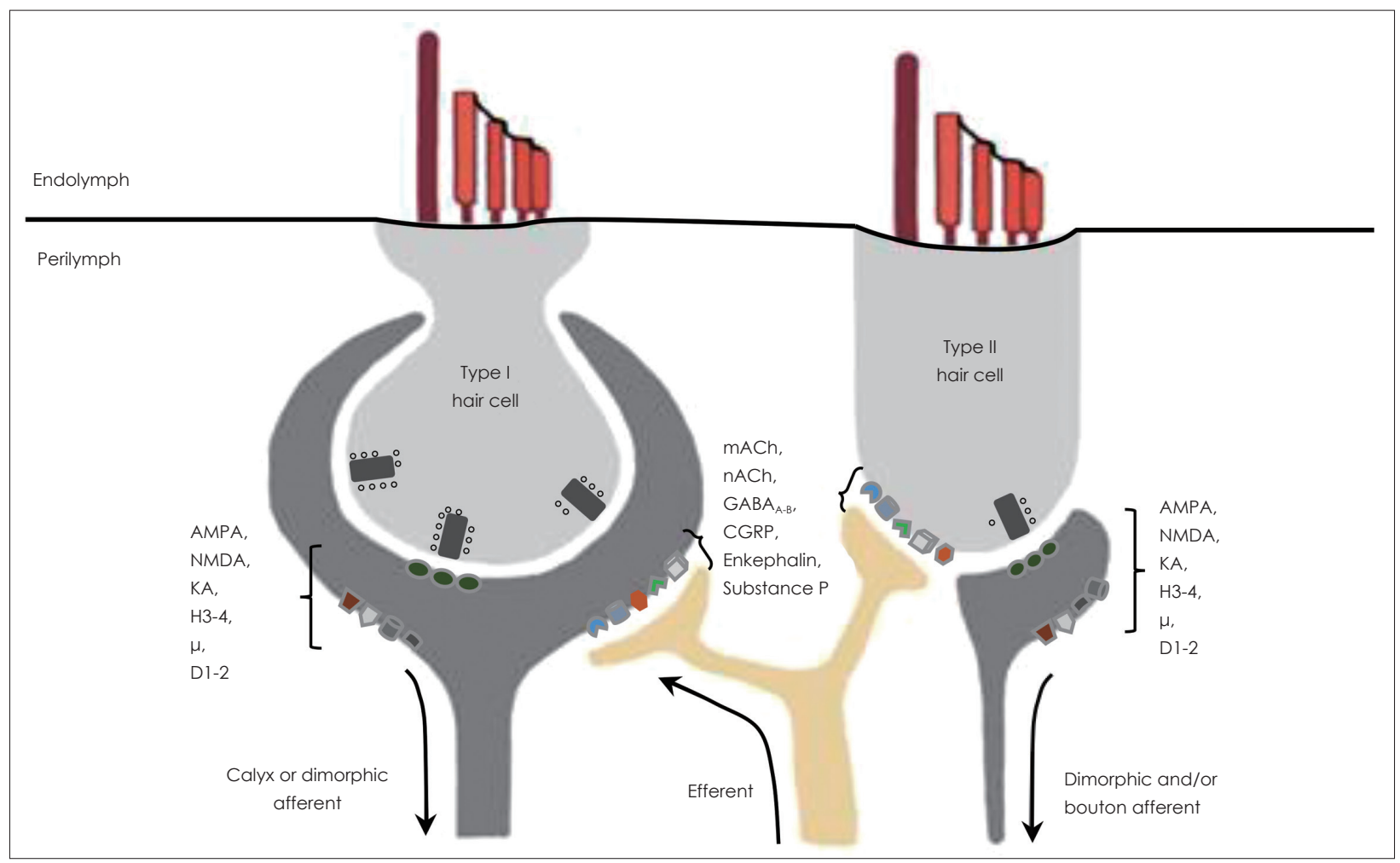

Fig. 2. Schematic illustration of type I (left) and type II (right) hair cell are shown with primary afferent and efferent neurons. Calyx or dimorphic afferents (gray fibers) envelop most of the basolateral surface of the type I hair cell and bouton and/or dimorphic afferents innervate the type II hair cell (gray fibers). Efferent axons arising from the brainstem contact the external surface of calyx afferent and make direct contact with the basolateral surfaces of type II hair cell (green fiber). Synaptic vesicles are tethered to the synaptic ribbons and release glutamate to trigger action potentials in primary afferent neurons. Efferent neurons modulate afferent neural responses. Possible targets of pharmacological agents include AMPA, NMDA, KA, H3-4, GABA $A_{A-B}, \mu$-opioid, D1-2, nACh, mACh, CGRP, enkephalin, and substance $P$ receptors in the postsynaptic membranes of vestibular afferent fibers. AMPA: $\alpha$-amino-3-hydroxy-5-methyl-4isoxazolepropionic acid, NMDA: N-methyl-D-aspartic acid, KA: kainic acid, H3-4: histamine 3-4, GABA $A_{A-B}$ : $\gamma$-amino butyric acid ${ }_{A-B}$, D12: dopamine 1-2, nACh: nicotinic acetylcholine, mACh: muscarinic acetylcholine, CGRP: calcitonin gene-related protein.

Glutamate interacts with ionotropic receptors such as $\alpha$-amino3-hydroxy-5-methyl-4-isoxazolepropionic acid (AMPA), Nmethyl-D-aspartic acid (NMDA), and kainic acid (KA) as well as metabotropic receptors such as metabotropic glutamate receptor 1-8 (mGluR1-8) [1,6]. Ionotropic and metabotropic glutamate receptors are located on the vestibular primary afferent dendrites. These receptors mediate the input signals from vestibular hair cells and also between primary afferents and second order vestibular nuclei neurons (see below).

AMPA is a major glutamate receptor in the inner ear. The AMPA response to glutamate produces a postsynaptic increase in intracellular cations including especially $\mathrm{Na}^{+}$postsynaptically; these cations thus play a functional role in AMPA-mediated depolarization of vestibular afferent neurons [7]. Immunohistochemical studies have suggested that AMPA receptor subunits GluR1, GluR2-3, and GluR4 are expressed in mammalian vestibular hair cells and calyx afferents $[3,7]$. The application of a specific AMPA/KA antagonist (1.5 mM DNQX) to the mouse vestibular afferents blocked AMPA responses [7]. The neurons of the vestibular nuclei also express
AMPA EAA receptors. Popper, et al. [8] used immunohistochemistry in the vestibular nuclei of the chinchilla and found ionotropic AMPA receptor subunits (GluR2-3) in the most neurons, (GluR1) in some neurons, and (GluR4) in the fewest number of neurons.

There is evidence in support of the presence of the NMDA receptors on both vestibular hair cells and afferent neurons. The NMDA receptor (NMDAR) subunits NMDAR1, NMDAR2A, NMDAR2B, NMDAR2C, and NMDAR2D are reportedly expressed in rat vestibular afferent neurons [6]. Electrophysiological studies have suggested that the application of NMDA antagonists [2-amino-5-phosphonopentanoic acid (AP5) and 7-chloro-kynurenic acid (7ClKyn)] decreased spontaneous spike discharge in vestibular afferents [9]. In addition, an electrophysiological study using whole-cell patch clamp methods in the brainstem reported NMDA receptors contribute to afferent synaptic transmission in the medial vestibular nucleus (MVN) of the rat [10]. These studies suggest that NMDA receptors contribute to afferent neurotransmission in both the peripheral and central vestibular system. 
Evidence for KA glutamate-receptors in the vestibular system is far less compelling, and glutamate affinity at ionotropic KA receptors seems to be low. There are five KA receptor subunits (GluR5-7 and KA1-2); however, GluR5, GluR6, KA1, and KA2 were only immunochemically expressed in mammalian vestibular ganglia [6]. Several pharmacological studies have suggested that KA receptors like other glutamate receptors act during afferent neurotransmission in mammalian vestibular neurons. Trimetazidine, a potent antagonist of KA receptor, blocked kainate-induced excitatory responses in the rat vestibular afferent neurons [11]. AMPA/KA receptor antagonists, CNQX and NBQX, were delivered to the interstitial fluids of the inner ear through perilymphatic perfusion and the effect on vestibular compound action potentials using linear vestibular sensory evoked potentials (VsEPs) showed VsEP response amplitudes were significantly reduced [12]. Evidence for metabotropic glutamate receptors in the vestibular pathways is far less compelling, with a limited number of studies. Numerous studies have shown that the afferents innervating vestibular hair cells are triggered by responses to the activation of glutamate receptors, and glutamate is a major afferent neurotransmitter at both peripheral and central afferent synapses.

\section{ACh receptors}

The primary neurotransmitter of vestibular efferent synapses is acetylcholine $[13,14]$. In mammals including humans, the activity of choline acetyltransferase (ChAT), which synthesizes ACh, and acetylcholinesterase (AChE), which inactivates $\mathrm{ACh}$, was found in numerous bouton terminals at the basal surface of the vestibular hair cells $[13,15]$. Two major classes of ACh receptors found in the vestibular neuroepithelium are nicotinic $\mathrm{ACh}$ receptor ( $\mathrm{nAChR}$ ) and muscarinic ACh receptor (mAChR). Over the last decade, Holt and his colleagues have focused on addressing the function of the vestibular efferent system and reported that vestibular efferent neurons produce both excitation and inhibition of vestibular responses in animals $[13,14,16]$. Their findings indicate that efferent-mediated inhibition results from the activation of $\alpha 9 \alpha 10 \mathrm{nACh}$ receptors on type II vestibular hair cells and direct efferent-mediated excitation of vestibular afferents is mediated by mACh (mAChR1, 3, 5) and/or nACh receptors $(\alpha 4, \alpha 6$, and $\beta 2)$ [14].

$\mathrm{nACh}$ receptors are ionotropic receptors (i.e., ligand-gated ion channels) composed of diverse subunits: $\alpha 3, \alpha 5-7, \alpha 9 \alpha 10$, and $\beta 2-4$ in the vestibular end organs as well as $\alpha 2-7$ and $\beta 2-4$ in the vestibular afferent neurons $[13,14]$. Based on their inherent signaling mechanisms, nAChR-mediated responses are faster than mAChR-mediated responses. Most nAChRs control the membrane permeability to cations especially $\mathrm{Ca}^{2+}$ ions [17] and when activted lead to membrane depolarization and excitation of vestibular afferents. However, $\alpha 9 \alpha 10 \mathrm{nACh}$ receptors when activated increase $\mathrm{Ca}^{2+}$ entry into the cell, which in turn activates $\mathrm{Ca}^{2+}$-dependent $\mathrm{K}^{+}$(SK) channels. This produces membrane hyperpolarization, inhibition of neurotransmitter release and a reduction in the excitatory drive on primary afferents [14].

In addition to $\mathrm{nACh}$ receptors, $\mathrm{mACh}$ receptors are metabotropic receptors (i.e., G-protein-coupled receptors) and its receptor subunits (m1-5) are expressed in mammalian vestibular end organs and Scarpa's ganglion [13,18]. Because of the G-protein-coupled receptor signaling mechanism, mAChRmediated responses should follow relatively slower kinetics than nAChRs. Despite the slow kinetics, mACh receptors have been the target of vestibular suppressants (e.g., scopolamine). Whole-cell patch clamp recordings of rat vestibular afferent neurons showed that the mAChR agonist, oxotremorine-M, significantly reduced outward polarizing $\mathrm{K}^{+}$current called "M-current," causing depolarization and excitation of the neurons [19]. Its action was blocked by atropine, an mAChR antagonist, thus suggesting the presence of $\mathrm{mAChRs}$ on vestibular afferent neurons. Recently using in vivo recordings, pharmacological reduction of M-current was shown to significantly alter peripheral vestibular afferent responses suggesting that efferent control of mAChRs may provide a means to modulate primary afferent response characteristics [20].

In the vestibular nuclei, specific nAChR and mAChR subunits were not clearly identified. Even in the vestibular efferent neurons of brainstem, ChAT (responsible for the synthesis of $\mathrm{ACh}$ ) is found only in some of the vestibular efferent neurons [13] suggesting that some of these neurons may not be mediated by $\mathrm{nAChR}$ and $\mathrm{mAChR}$. Intracellular recordings of rat MVN have shown that $\mathrm{nACh}$ and $\mathrm{mACh}$ receptor agonists produced membrane depolarization [21]. Extracellular recordings in all four major vestibular nuclei (i.e., medial, lateral, inferior, and superior) of the rat vestibular nuclear complex have indicated that $\mathrm{nACh}$ and $\mathrm{mACh}$ receptor agonists (carbachol and muscarine) increased spontaneous firing rates and established that the effect of ACh agonists was highest in the MVN [22]. These studies indicate that both nACh and $\mathrm{mACh}$ receptors are present and influence the excitability of the mammalian vestibular nucleus neurons.

\section{GABA receptors}

The role of GABA in the vestibular system has been widely debated, but a clear consensus has not been reached. GABA receptors are divided into three types [23]: 1) $\mathrm{GABA}_{\mathrm{A}}$ receptor is an ionotropic receptor controlling a ligand-gated $\mathrm{Cl}^{-}$ 
ion channel, 2) $\mathrm{GABA}_{\mathrm{B}}$ receptor is a metabotropic receptor which interacts with $G_{i}$ to inhibit adenylyl cyclase, upregulates $\mathrm{K}^{+}$channels, and downregulates $\mathrm{Ca}^{2+}$ channels, and 3) $\mathrm{GABA}_{\mathrm{C}}$ receptor is a transmitter-gated $\mathrm{Cl}^{-}$channel but is not likely expressed in the vestibular system. Meza [24] and her research group completed a considerable amount of work studying mechanisms of GABA and its receptors in the vestibular sensory neuroepithelium. GABA synthesizing enzymes, L-glutamate decarboxylase (GAD) and GABA transaminase (GABA-T) are present as well as $\mathrm{GABA}_{\mathrm{A}}$ receptor-subunits $\gamma 1, \gamma 2$, and $\gamma 3$ are expressed in mammalian vestibular hair cells and Scarpas's ganglion [24]. These early findings were interpreted as indicating that GABA may function as an afferent neurotransmitter in vestibular hair cells. However, this hypothesis has not received convincing support. The presence of GABA in vestibular epithelia is highly variable across species especially within hair cells. GABA-like immunoreactivity in efferent endings of the mammal was reported in the squirrel monkey but not rat or guinea pig and in the bird GABA labeling was reported for the pigeon with weak labeling in the chicken [25]. Electrophysiological studies also showed that the application of GABA agonists and antagonists had no direct effect on the vestibular afferents [26]. These investigators plausibly argued that GABA is not the neurotransmitter in the afferent synapse, but may be a facilitator of glutamate release.

Rather than being a primary afferent transmitter, GABA may have a modulatory role being co-released by efferent neurons and serve to modulate afferent activity in both the vestibular and auditory systems rather than act as the principal hair cell transmitter driving sensory discharge patterns [13]. The mechanism of GABA action remains unclear, but it seems to be involved to some extent in modulating $\mathrm{Ca}^{2+}$ signalling mediated by inhibition of $\mathrm{Ca}^{2+}$ channels presynaptically and/ or activation of $\mathrm{Cl}^{-}$channels. Thus, it may indirectly reduce neurotransmitter release presynaptically to disfacilitate postsynaptic cells $[13,26]$.

Central vestibular nuclei are known to receive potent inhibitory inputs mediated by $\mathrm{GABA}_{\mathrm{A}}$ and $\mathrm{GABA}_{\mathrm{B}}$ receptors. These GABAergic inputs arise primarily from commissural fibers of vestibular nuclei and cerebellum [5]. GABA $A_{A}$ receptor agonists including diazepam, lorazepam and clonazepam as well as $\mathrm{GABA}_{\mathrm{B}}$ receptor agonists, baclofen, are the most widely used benzodiazepines and these act in the central vestibular sensory pathways $[27,28]$.

\section{Histamine receptors}

Histamine and its four receptors ( $\mathrm{H} 1, \mathrm{H} 2, \mathrm{H} 3$, and H4) have been identified in the vestibular sensory pathway: $\mathrm{H} 1, \mathrm{H} 2$, and $\mathrm{H} 3$ receptors in the vestibular hair cells [29]; $\mathrm{H} 3$ and $\mathrm{H} 4$ receptors in the vestibular afferents [30,31]. All histamine receptors are metabotropic, with four different G-protein coupled receptors acting through a second messenger intracellularly. Evidence for histamine receptors in the vestibular system suggests that they may perform an important role in the control of vestibular function.

Even though H1-3 receptors are expressed and their activation induces an influx of $\mathrm{Ca}^{2+}$ in vestibular hair cells, intracellular recordings of guinea pig vestibular hair cells have shown that $\mathrm{H} 3$ receptors may mediate a notably larger increase in $\mathrm{Ca}^{2+}$ permeability (larger influx of $\mathrm{Ca}^{2+}$ ) compared to $\mathrm{H} 1$ and $\mathrm{H} 2$ receptors [29]. Recently, H4 antagonist JNJ7777120 has been studied in Scarpa's ganglion of the rat and electrophysiological recordings showed reversible inhibitory effects elicited by the $\mathrm{H} 4$ receptor antagonist without subsequent excitatory action [31]. However, this effect may not be shared by central vestibular nucleus neurons. The findings suggest that $\mathrm{H} 4$ receptors mediate an excitatory action in vestibular primary afferent neurons. Histamine also modulates the neural activities of the second order neurons in the vestibular nuclei and its various effects on the vestibular nuclei have been reported in several electrophysiological studies. Dimaprit, a selective $\mathrm{H} 2$ receptor agonist, produced an excitatory action on rat MVN neurons, and its effect was blocked by ranitidine, a selective $\mathrm{H} 2$ receptor antagonist, blocked its effect [32]. Betahistine (strong $\mathrm{H} 3$ receptor antagonist and weak H1 receptor agonist), produced a weak excitatory action, but significantly reduced the excitatory effect elicited by histamine on the MVN neurons $[32,33]$. Thus, the effectiveness of histamine receptor antagonists on motion sickness, vertigo and dizziness can be explained by their action in reducing the excitatory actions in the mammalian vestibular nuclei and/or in the vestibular periphery.

\section{Opioid peptide receptors}

The opioid receptors preferentially activated by the enkephalins largely comprise three receptor subtypes ( $\mu-, \mathrm{k}-$, and $\delta$-receptors; G-protein coupled receptors) based on their pharmacological characteristics [34]. In addition to three major receptor subtypes, the opioid-like orphan (ORL1) receptor is another member of the opioid receptor family and is specifically activated by nociceptin. Enkephalins and opioid receptors were found in the vestibular sensory pathway: $\mu$ - and kopioid receptors in the vestibular hair cells and afferent neurons; $\delta$-opioid and ORL1 receptors in the MVN neurons [4,13,35]. Opioid peptides may be candidates for modulating synaptic transmission in the vestibular afferent neurons. Whole-cell patch clamp recordings of amphibian vestibular hair cells showed that vestibular afferents were excited by $\mu$-receptor 
agonists at the postsynaptic level (postsynaptic activation of afferent neurons) and inhibited by k-receptor agonists at the presynaptic level (inhibition of hair cells), reducing $\mathrm{Ca}^{2+}$ currents in the hair cells [36]. This study suggests that the vestibular afferents are regulated by the complex of opioid receptors. Electrophysiological data from mammalian MVN neurons indicated that the $\delta$-opioid receptor agonists inhibited rotation- and glutamate-induced firing rates [37] and ORL1 receptor agonists also inhibited the spontaneous discharge rates [35]. These results suggest that enkephalins modulate afferent transmission at both the peripheral and the central vestibular levels.

\section{Dopamine receptors}

Dopamine receptors have been divided into two families: a D1-like family of dopamine receptors including D1 and D5 as well as a D2-like family including D2, D3, and D4 (all Gprotein coupled receptors) [38]. Several findings support a possible involvement of dopamine as a modulator of excitatory neurotransmission at postsynaptic afferent terminals [38,39]. In the mammalian vestibular neuroepithelium, immunochemical evidence has indicated that dopamine D1 and D2 receptors are expressed in both type I and type II vestibular hair cell membranes [40]. Pharmacological studies using extracellular recordings showed that frog vestibular afferents were excited by EAA agonists and the excitation was suppressed by co-administration of D1 or D2 agonists [39]. This result suggests that the responses of D1 and D2 receptors act not only to modulate glutamate receptors postsynaptically, but also may have a protective function in the vestibular dendrites. In the vestibular nuclei, guinea-pig MVN neurons were depolarized only by D2 agonists; D1 receptors were not involved, suggesting the presence of $\mathrm{D} 2$ receptors in the mammalian MVN [41]. In clinical applications, dopaminergic receptor antagonists such as prochlorperazine, promethazine, and domperidone [27] might exert a modulatory action on vestibular afferent neurons.

\section{CGRP receptors}

Immunochemical studies found that ChAT and CGRP probably co-exist in vestibular efferent neurons $[13,42]$. Electrophysiological data confirmed the function of CGRP receptor and showed that CGRP released from efferent neurons increased vestibular afferent activities [3]. Sewell and Starr [43] argued that CGRP released from efferent neurons produces an increase in spontaneous discharge rate and this increases the probability of excitatory postsynaptic potentials. Recently, mice with loss of $\alpha$ CGRP gene (-/-) showed a significant reduction in Vestibular Ocular Reflex (VOR) gain, suggesting
CGRP dependent effects in peripheral and/or central vestibular pathways [42]. Taken together, the results of these studies regarding CGRP suggest that efferent fibers making contact with both calyx afferents and type II hair cells contain CGRP and CGRP may exert modulatory effects on ACh receptors to increase the excitability of peripheral vestibular afferents.

Immunocytochemistry studies have reported the presence of substance $P$ in mammalian vestibular hair cells and Scarpa's ganglion $[3,4,44]$ and investigated the coexistence of substance $\mathrm{P}$ and CGRP in the rat vestibular end organs using immunocytochemistry. Usami, et al. [44] revealed three different types of immunoreactivities localized within as well as beneath the sensory epithelia in rats. Since most immunoreactivity data clearly indicate that CGRP is associated with efferent fibers, the finding of substance $P$ also supports the coexistence of the two and suggests a possible role for substance $\mathrm{P}$ in modulating the peripheral vestibular system.

\section{Conclusion}

The current review of the literature reveals that basic research on the pharmacological targets of drugs and medications has provided many answers to questions about the biochemical, molecular and functional nature of neural signaling in the vestibular sensory pathways. If we are to understand the action of drugs and medications, we must first understand the target receptors through which drugs and medications act to produce clinical outcomes. A considerable amount of effort has been carried out to identify neurotransmitters and modulators in the vestibular system using in vitro animal preparations. Medications work by mimicking, suppressing or otherwise altering these normal signaling processes. One may speculate and infer that the lessons learned from study of target processes and mechanisms, although often discovered in vitro, also apply to drug actions in the intact animal. However, in many cases particularly in the case of new and promising medications, drug actions in the intact animal are not fully understood. Therefore, developing reliable direct in vivo assessment tools for the study of vestibular sensory pathways will be important to accurately quantify drug effects on vestibular function. Clinically, in vivo research on vestibular pharmacological targets may aid the development of more accurate and effective intervention strategies for the treatment of dizziness and vertigo.

\section{Acknowledgments}

We thank Drs. Sherri Jones and J. Chris Holt for their comments on an earlier version of this work. 


\section{Conflicts of interest}

The authors have no financial conflicts of interest.

\section{REFERENCES}

1) Watkins JC, Evans RH. Excitatory amino acid transmitters. Ann Rev Pharmacol Toxicol 1981;21:165-204.

2) Hilding D, Wersäll J. Cholinesterase and its relation to the nerve endings in the inner ear. Acta Otolaryngol 1962;55:205-17.

3) Guth PS, Perin P, Norris CH, Valli P. The vestibular hair cells: posttransductional signal processing. Prog Neurobiol 1998;54:193-247.

4) Soto E, Vega R, Seseña E. Neuropharmacological basis of vestibular system disorder treatment. J Vestib Res 2013;23:119-37.

5) Highstein SM, Holstein GR. The anatomy of the vestibular nuclei. Prog Brain Res 2006;151:157-203.

6) Niedzielski AS, Wenthold RJ. Expression of AMPA, kainate, and NMDA receptor subunits in cochlear and vestibular ganglia. J Neurosci 1995;15(3 Pt 2):2338-53.

7) Rabejac D, Devau G, Raymond J. AMPA receptors in cultured vestibular ganglion neurons: detection and activation. Eur J Neurosci 1997;9:221-8.

8) Popper P, Rodrigo JP, Alvarez JC, Lopez I, Honrubia V. Expression of the AMPA-selective receptor subunits in the vestibular nuclei of the chinchilla. Mol Brain Res 1997;44:21-30.

9) Soto E, Flores A, Eróstegui C, Vega R. Evidence for NMDA receptor in the afferent synaptic transmission of the vestibular system. Brain Res 1994;633:289-96.

10) Sakai N, Ujihara H, Ishihara K, Sasa M, Tanaka C. Electrophysiological and pharmacological characteristics of ionotropic glutamate receptors in medial vestibular nucleus neurons: a whole cell patch clamp study in acutely dissociated neurons. Jpn J Pharmacol 1996; 72:335-46.

11) Dayanithi G, Desmadryl G, Travo C, Chabbert C, Sans A. Trimetazidine modulates AMPA/kainate receptors in rat vestibular ganglion neurons. Eur J Pharmacol 2007;574:8-14.

12) Irons-Brown SR, Jones TA. Effects of selected pharmacological agents on avian auditory and vestibular compound action potentials. Hear Res 2004;195:54-66.

13) Holt JC, Lysakowski A, Goldberg JM. The efferent vestibular system. In: Ryugo DK, Fay RR, Popper AN, editors. Auditory and vestibular efferents. New York, NY: Springer;2011. p.135-86.

14) Holt JC, Kewin K, Jordan PM, Cameron P, Klapczynski M, McIntosh JM, et al. Pharmacologically distinct nicotinic acetylcholine receptors drive efferent-mediated excitation in calyx-bearing vestibular afferents. J Neurosci 2015;35:3625-43.

15) Ishiyama A, Lopez I, Wackym PA. Choline acetyltransferase immunoreactivity in the human vestibular end-organs. Cell Biol Int 1994; 18:979-84.

16) Jordan PM, Parks XX, Contini D, Holt JC. A review of synaptic mechanisms of vestibular efferent signaling in turtles: extrapolation to efferent actions in mammals. J Vestib Res 2013;23:161-75.

17) Weisstaub N, Vetter DE, Elgoyhen AB, Katz E. The alpha9alpha10 nicotinic acetylcholine receptor is permeable to and is modulated by divalent cations. Hear Res 2002;167:122-35.

18) Wackym PA, Chen CT, Ishiyama A, Pettis RM, López IA, Hoffman L. Muscarinic acetylcholine receptor subtype mRNAs in the human and rat vestibular periphery. Cell Biol Int 1996;20:187-92.

19) Pérez C, Limón A, Vega R, Soto E. The muscarinic inhibition of the potassium $\mathrm{M}$-current modulates the action-potential discharge in the vestibular primary-afferent neurons of the rat. Neuroscience 2009; 158:1662-74.

20) Lee C, Holt JC, Jones TA. The effect of M-current modulation on mammalian vestibular responses to transient head motion. J Neurophysiol 2017 Aug 30 [Epub ahead of print]. https://doi.org/10.1152/ jn.00384.2017.
21) Phelan KD, Gallagher JP. Direct muscarinic and nicotinic receptormediated excitation of rat medial vestibular nucleus neurons in vitro. Synapse 1992;10:349-58.

22) Sun Y, Waller HJ, Godfrey DA, Rubin AM. Spontaneous activity in rat vestibular nuclei in brain slices and effects of acetylcholine agonists and antagonists. Brain Res 2002;934:58-68.

23) Molinoff $P B$. Neurotransmission and the central nervous system. In: Brunton LL, Chabner BA, Knollman B, editors. Goodman \& Gilman's the pharmacological basis of therapeutics, 12th ed. New York: McGraw-Hill Companies;2010. p.378-9.

24) Meza G. Modalities of GABA and glutamate neurotransmission in the vertebrate inner ear vestibule. Neurochem Res 2008;33:1634-42.

25) Matsubara A, Usami S, Fujita S, Shinkawa H. Expression of substance $\mathrm{P}, \mathrm{CGRP}$, and GABA in the vestibular periphery, with special reference to species differences. Acta Otolaryngol Suppl 1995;519: 248-52.

26) Cortes C, Galindo F, Galicia S, Cebada J, Flores A. Excitatory actions of GABA in developing chick vestibular afferents: effects on resting electrical activity. Synapse 2013;67:374-81.

27) Hain TC, Uddin M. Pharmacological treatment of vertigo. CNS Drugs 2003; 17:85-100.

28) Lee C. Effects of pharmacological agents on mammalian vestibular function [dissertation]. Lincoln(NE): University of Nebraska-Lincoln;2016.

29) Tomoda K, Nagata M, Harada N, Iwai H, Yamashita T. Effect of histamine on intracellular $\mathrm{Ca} 2+$ concentration in guinea pig isolated vestibular hair cells. Acta Otolaryngol Suppl 1997;528:37-40.

30) Tritto S, Botta L, Zampini V, Zucca G, Valli P, Masetto S. Calyx and dimorphic neurons of mouse Scarpa's ganglion express histamine $\mathrm{H} 3$ receptors. BMC Neurosci 2009; 10:70.

31) Desmadryl G, Gaboyard-Niay S, Brugeaud A, Travo C, Broussy A, Saleur A, et al. Histamine H4 receptor antagonists as potent modulators of mammalian vestibular primary neuron excitability. Br J Pharmacol 2012;167:905-16.

32) Wang JJ, Dutia MB. Effects of histamine and betahistine on rat medial vestibular nucleus neurones: possible mechanism of action of anti-histaminergic drugs in vertigo and motion sickness. Exp Brain Res 1995;105:18-24.

33) Dutia MB. Betahistine, vestibular function and compensation: in vitro studies of vestibular function and plasticity. Acta Otolaryngol Suppl 2000;544:11-4.

34) Dhawan BN, Cesselin F, Raghubir R, Reisine T, Bradley PB, Portoghese PS, et al. International Union of Pharmacology. XII. Classification of opioid receptors. Pharmacol Rev 1996;48:567-92.

35) Sulaiman MR, Niklasson M, Tham R, Dutia MB. Modulation of vestibular function by nociceptin/orphanin FQ: an in vivo and in vitro study. Brain Res 1999;828:74-82.

36) Vega R, Soto E. Opioid receptors mediate a postsynaptic facilitation and a presynaptic inhibition at the afferent synapse of axolotl vestibular hair cells. Neuroscience 2003;118:75-85.

37) Kawabata A, Sasa M, Ujihara H, Takaori S. Inhibition by enkephalin of medial vestibular nucleus neurons responding to horizontal pendular rotation. Life Sci 1990;47:1355-63.

38) Beaulieu JM, Gainetdinov RR. The physiology, signaling, and pharmacology of dopamine receptors. Pharmacol Rev 2011;63:182-217.

39) Andrianov GN, Ryzhova IV, Tobias TV. Dopaminergic modulation of afferent synaptic transmission in the semicircular canals of frogs. Neurosignals 2009;17:222-8.

40) Drescher MJ, Cho WJ, Folbe AJ, Selvakumar D, Kewson DT, AbuHamdan MD, et al. An adenylyl cyclase signaling pathway predicts direct dopaminergic input to vestibular hair cells. Neuroscience 2010; 171:1054-74.

41) Vibert N, Serafin M, Crambes O, Vidal PP, Mühlethaler M. Dopaminergic agonists have both presynaptic and postsynaptic effects on the guinea-pig's medial vestibular nucleus neurons. Eur J Neurosci 1995; 7:555-62. 
42) Luebke AE, Holt JC, Jordan PM, Wong YS, Caldwell JS, Cullen KE. Loss of $\alpha$-calcitonin gene-related peptide ( $\alpha \mathrm{CGRP}$ ) reduces the efficacy of the Vestibulo-Ocular Reflex (VOR). J Neurosci 2014;34: 10453-8.

43) Sewell WF, Starr PA. Effects of calcitonin gene-related peptide and efferent nerve stimulation on afferent transmission in the lateral line organ. J Neurophysiol 1991;65:1158-69.

44) Usami S, Hozawa J, Ylikoski J. Coexistence of substance P and calcitonin gene-related peptide-like immunoreactivities in the rat vestibular endorgans. Acta Otolaryngol Suppl 1991;481:166-9. 